\title{
Knowledge of sexual abuse amongst female students in Malawi
}

\author{
R Dzimadzi, MSc Nursing \\ H Klopper, PhD; MBA \\ Professor, School of Nursing Science, North-West University
}

Post-graduate student, Department of Nursing Education, University of the Witwatersrand

Keywords: Key words: Female students, Malawi, sexual abuse, sexual abuse knowledge.

\section{Correspondence address:}

Prof Hester Klopper

Private Bag X 6001

School of Nursing Science

North-West University (Potchefstroom

Campus)

Potchefstroom, 2520

Tel : (018) 299-1829/1830

Fax : (018) 299-1827

E-mail: Hester.Klopper@nwu.ac.za

\section{Abstract: Curationis 30(3): $x-y$}

ABSTRACT

Sexual abuse is an increasing problem in Malawi amongst female students, and is associated with physical and mental health problems. This study aimed to determine existing knowledge of sexual abuse amongst female students in tertiary education institutions in Malawi. A descriptive, comparative, quantitative and contextual research design was used. Participants $(n=219)$ were selected through systematic random sampling from a population of female students aged 18 to 21 , at fifteen $(n=15)$ tertiary education institutions in Malawi. Sexually abusive behaviours demonstrated by a lover and friend were interpreted as not being abusive. There were no significant differences in knowledge of sexual abuse between the abused and non-abused respondent groups $(\mathrm{p}>0.05)$. The overall prevalence rate of sexual abuse was $41 \%$. Common forms of sexual abuse experienced were touching of breasts (54.4\%) and attempted sexual intercourse $(47.8 \%)$. Completed sexual intercourse was experienced by $18.9 \%$ of the respondents. The majority reported that they were sexually abused by men $(98.9 \%)$. Twenty one percent experienced more than one sexually abusive incident and some respondents were abused by friends (30\%). The abusers mostly used physical threats. Only $55.6 \%$ reported their sexual victimisation to others. Female students aged 18 to 21 in tertiary education institutions in Malawi had some knowledge of sexual abuse, but there were deficits in the interpretation of sexually abusive behaviours. The majority of abusers were male adolescents and young adults. Respondents should know what the Malawi law stipulates and what can be done to control and prevent sexual abuse. The information obtained from the study was used to develop guidelines for sexual abuse prevention programmes.

\section{Introduction and background information}

Sexual abuse is a form of violence, which has mostly affected females (Chen, Tyler, Whitbech \& Hoyt, 2004:2; Keeton, 2004:313) from all age groups and across cultures. Sexual abuse experiences are associated with adverse psychological and physical consequences. Such consequences include public health, clinical care and human rights issues. Violence is a leading cause of female mortality and disability worldwide (Fanslow \& Norton, 1994; Ryan \& King 1992). In this research a student refers to a person aged between 18 and 21 years, who attended a tertiary education institution in Malawi during the time in which the research was conducted. The definition of sexual abuse adopted in this study is derived from the definitions by Kempe and Kempe (1978, cited in Wilson \& James, 1995: 157) and Baker and Duncan (1985:458) and can be summarised as 'the involvement of a female student in sexual activity to which the victim is unable to give informed consent and that is intended to sexually gratify the abuser'. Sexual abuse can involve acts of sexual contact and/or noncontact. According to Monteleone and Brodeur (1998:22) acts of sexual contact include, fondling of genitals, oral-genital 
sex, penetration with a finger or object, sexual intercourse and sodomy. Other acts such as the touching of breasts or buttocks are not regularly mentioned in literature, but they are also sexually abusive acts. In Malawi, kissing is not a common practice. Kissing in a sexual way could therefore be regarded as abuse if done without consent. Non-contact involves exhibition of sexual organs by the abuser or exposing of genitals to the abuser, watching the abuser masturbate, looking at pornographic material, being filmed for pornographic use and sexual harassment (Dzimadzi, 2002: 18).

Studies conducted in developed countries (China, Malaysia and South Africa) display prevalence rates for various forms of child sexual abuse in females (including non-contact and contact) ranging from $6 \%$ to $53.2 \%$ (Tang, 2002:24; Amar, Wong, \& Khatijah, 1996:488; Madu \& Peltzer, 2001:312). Higher rates were obtained in a study conducted in Geneva by Halperin, Bourier, Mounoud, Halperin, Bouvier, Jaffe, Mounoud, Pawlak, Laederach, Wicky, \& Astie (1996:1328) (33\% for girls). In the United States non-voluntary or coercive sexual intercourse has been reported by $7 \%$ to $17 \%$ of adolescents and young adults (Nagy, Diclemente \& Adcock, 1995:945).

A search of literature and databases found few studies on knowledge about sexual abuse. Calvert and MunsieBenson (1999) is one such a study that was conducted in the USA, which indicated that participants were fairly knowledgeable about child sexual abuse. However, knowledge gaps were found in men, unmarried respondents, respondents who had no children, respondents in younger age groups and respondents with low incomes and limited education. Poor sexual knowledge has been identified as an individual risk factor that increases people's vulnerability to sexual victimisation (McCabe, 1993:379). Other factors include a lack of sex education (Fenwick, 1994:54) and a lack of knowledge about sexual abuse preventive skills (Haseltine \& Miltenberger, 1990:188). For example, in Malawi written information such as flyers and leaflets, that could equip literate children and adolescents with sexual abuse knowledge, are not available (Dzimadzi, 2002:3).

Sexual abuse occurs in the Malawian society, and cases are reported since the advent of freedom of press and expression. However, many of these cases still go unreported, because in some parts of Malawi, cultural traditions condone sexual abuse of females in the form of initiation ceremonies (Dzimadzi, 2002: 21). The lack of reporting of sexual abuse in Malawi may be influenced by the Malawians' lack of awareness of human rights (Human Rights Needs Assessment Survey, 1999). As a result, female students might not realise that they are abused and that their rights are violated since acts of sexual abuse are regarded as being culturally acceptable. Apart from the police, where abuse is reported, there are no sexual abuse clinics, crisis centres, help lines or related services where victims could potentially report their victimisation. According to the Ministry of Education, Malawi's basic school curriculum does not offer sex education. In a study on sexual health knowledge, attitudes and practices, Kawala (2000) identified that Malawian high school adolescents have poor knowledge of sexual issues, increasing their vulnerability to sexual victimisation (McCabe, 1993:380). As females are more vulnerable to sexual abuse, their risks for acquiring sexually transmitted diseases and suffering psychological effects are higher than that of males. In Malawi it is estimated that $15 \%$ of the $15-49$ years age group are currently infected with HIV (NACP, 2001), indicating the dire need to conduct research about female students' knowledge about sexual abuse.

\section{Research questions}

The following research questions were raised and guided the research aims and objectives:

What knowledge do female
students in tertiary education
institutions in Malawi have
regarding sexual abuse?
Is there any difference in the
knowledge of sexual abuse
between the abused and non-
abused female students in
tertiary education institutions in
Malawi?
To which tribes do the abused
and non-abused female
students in tertiary education
institutions in Malawi belong?
What is the prevalence of sexual
abuse experienced amongst
female students?
What are the common forms of

sexual abuse experienced amongst female students?

- What are the profiles of sexual abuse perpetrators?

- What guidelines can be formulated to develop sexual abuse prevention programmes?

\section{Research aim and objectives}

The aim of the study was to determine the knowledge about sexual abuse and its prevalence amongst female students in tertiary education institutions in Malawi. To achieve this aim the following objectives were set:

- To describe knowledge of what constitutes sexual abuse amongst female students.

- $\quad$ To compare knowledge about sexual abuse between abused and non-abused female students in tertiary education institutions in Malawi.

- To compare the distribution of tribes between abused and nonabused female students in tertiary education institutions in Malawi.

- To determine the prevalence of sexual abuse experienced by female students.

- To determine the common forms of sexual abuse experienced by female students.

- To describe the profiles of sexual abuse perpetrators.

- To formulate guidelines for development of sexual abuse prevention programmes.

\section{Research design and method}

A descriptive, comparative, quantitative and contextual research design was used in this study. The research was conducted at fifteen tertiary education institutions (there are twenty in total) in Malawi to capture female students. The five institutions not used in the study, were excluded for the following reasons: one institution was utilized for the pilot study; two institutions were indefinitely closed due to student strikes; one had to change its academic calendar due to financial constraints resulting in the fact that students were not attending class during the period of data collection; and one institution did not have female 
students in the age group used in this study. The population consisted of female students, aged between 18 and 21 years. This age range was selected as it is a group that would not require consent from parents to participate in the study. Participants had to be single in order to exclude sexual abuse issues related to marriage. The total population of female adolescents in the institutions was approximately $1850(\mathrm{~N}=1850)$. All cultures were incorporated in the population. The researcher with the assistance of a statistician, established the desired sample $(n=228)$ based on an expected sexual abuse prevalence rate of $40 \%$. The rate was determined after reviewing available literature on such rates in developing countries with characteristics similar to Malawi. At $90 \%$ confidence the sample size was estimated to within 5\% accuracy. Systematic random sampling was used and the sampling interval width (k) was established as the eighth element from the sampling frame. Administrators and the researcher or research assistants identified every eighth individual on the list, explained the purpose and process of the study, then obtained consent for participation. A pilot study was conducted at one of the tertiary level educational institutions to test the effectiveness of the research tool. The observations made during the pilot study were that all the participants preferred the English version of the questionnaire and that the questionnaire was completed by most participants within 25 minutes. Participants provided feedback that questions and instructions were clear.

Data was collected using an anonymous self-administered questionnaire. This was used due to the sensitive nature of the data. Open- and close ended questions were used. The questionnaire was prepared in both English and the local language, Chichewa. To assess the instrument's reliability Pearson's product moment correlation coefficient was used and a value of 0.80 was obtained which indicated a good relationship. A good relationship is obtained when the closer the numerical value of the correlation coefficient is to either extremes $(+1.0$ or $1.0)$, the closer the strength of the relationship between the two variables is to perfection (positive or negative) (De Vos, Strydom, Fouche \& Delport, 2006:242).

The questionnaire had four sections. The first section requested demographic information such as age, district of origin, tribe, living arrangements and year of study. The second section focused on knowledge regarding sexual abuse. It incorporated two questions to determine what the participants knew about sexual abuse. Respondents were asked to indicate "Yes", "No" or "Don't know" to a list of sexual behaviours. They were also asked to indicate whether sexual abuse was a crime and to give reasons for their answers. The third section consisted of questions related to the frequency and forms of sexual abuse experienced. A list of sexually abusive behaviours was presented and respondents indicated whether they had experienced these specific abuses. The last section included information profiles of sexual abuse perpetrators and details about the event(s). If respondents reported personal experiences of sexual abuse they were asked to indicate their age when first abused, whether the abuse was regular, their relationship to the abuser, age of abuser, whether threat was used, whether the abuse was reported, to whom it was reported and what action was taken following recognition of the abuse. Respondents were also requested to indicate general information that they wanted to know about sexual abuse in response to an open-ended question.

Ethical clearance was obtained from the research ethics committee of the University of the Witwatersrand and the National Health Science Research Committee in Malawi. Tertiary institutions where participants were studying also gave permission. The researcher, as well as research assistants, administered the questionnaires. Research assistants were trained by the researcher on the questionnaire's administration procedure. The procedure included seating participants, reading instructions, and managing participants who may present with emotional distress while completing the questionnaire. At each institution participants were assembled in one classroom and they were informed about the purpose of the study. Time to answer questions about the study was also provided. Those students who didn't want to participate were given the option to leave the room. The students who remained behind and agreed to participate in the study were given consent forms to sign. Autonomy was ensured by voluntary participation and assurance that they could withdraw from the study at any time without penalty. The participants were also assured of anonymity and confidentiality and seated in private rooms to allow them to respond unobserved by other students or members of the research team. After completion the questionnaire was placed in an envelope, sealed by the participant and placed in a box. The box was sealed and could only be accessed by the researcher. There was no way in which the responses on the questionnaire could be traced back to any participant, thus ensuring all participants' anonymity and since the researcher was the only person who had access to the questionnaires, confidentiality could also be ensured.

\section{Results}

Data was collected from 228 participants. Nine questionnaires were incomplete and therefore discarded. This report is an analysis of the remaining 219 questionnaires that were largely complete, providing a response rate of $96 \%$. Findings were described and summarised using descriptive statistics. Content analysis of open-ended questions was conducted. The statistical significance of differences between variables was established using Fishers Exact and Chi-square tests. The conventional level of significance, $p=$ 0.05 , was used. Due to natural variations entailed in human research, conclusions drawn about findings and generalisations beyond the data always involve a certain degree of uncertainty (Brink, 1989:89). A $p=0.05$ indicate that there is a probability of 5 in 100 that the findings may have a result of chance errors.

\section{Demographic information}

Respondents comprised female students aged between 18 and 21 years. More than half $(52.5 \%)$ of the respondents was 21 years of age and $51.1 \%$ were in their first year of study. Participants came from all the districts in Malawi and all the major and minor tribes were represented. Many respondents (53.4\%) lived in two parent households at the time of the study.

\section{Knowledge of sexual abuse}

All behaviours presented on the questionnaire are sexually abusive acts, therefore 'Yes' meant a positive response, indicating that the student had indeed experienced that specific abuse. Only $45.2 \%(n=99)$ of the respondents perceived touching of private parts by a friend as sexual abuse (refer to Table 1). 


\begin{tabular}{|l|c|c|c|c|}
\hline List of behaviours & Yes & No & $\begin{array}{c}\text { Don't } \\
\text { know }\end{array}$ & $\begin{array}{c}\text { No } \\
\text { response }\end{array}$ \\
\hline 1. An adult touches buttocks of a female child in a sexual way & $\begin{array}{c}70.8 \% \\
(155)\end{array}$ & $\begin{array}{c}10.0 \% \\
(22)\end{array}$ & $\begin{array}{c}14.2 \% \\
(31)\end{array}$ & $\begin{array}{c}5.0 \% \\
(11)\end{array}$ \\
\hline 2. Your lover touches your breasts without permission & $\begin{array}{c}48.9 \% \\
(107)\end{array}$ & $\begin{array}{c}25.9 \% \\
(59)\end{array}$ & $\begin{array}{l}18.3 \% \\
(40)\end{array}$ & $\begin{array}{c}5.9 \% \\
(13)\end{array}$ \\
\hline 3. A friend touches your private parts & $\begin{array}{c}45.2 \% \\
(99)\end{array}$ & $\begin{array}{c}23.7 \% \\
(52)\end{array}$ & $\begin{array}{l}25.6 \% \\
(56)\end{array}$ & $\begin{array}{c}5.5 \% \\
(12)\end{array}$ \\
\hline 4. A lover has sexual intercourse with you without permission & $\begin{array}{c}81.7 \% \\
(179)\end{array}$ & $\begin{array}{c}9.6 \% \\
(21)\end{array}$ & $\begin{array}{c}7.3 \% \\
(16)\end{array}$ & $\begin{array}{c}1.4 \% \\
(3)\end{array}$ \\
\hline 5. An adult kissing a female child in a sexual way & $\begin{array}{c}70.8 \% \\
(155)\end{array}$ & $\begin{array}{c}7.3 \% \\
(16)\end{array}$ & $\begin{array}{l}8.7 \% \\
(41)\end{array}$ & $3.2 \%$ \\
\hline 6. An adult asking a female child to touch his private parts & $\begin{array}{c}75.3 \% \\
(165)\end{array}$ & $\begin{array}{c}8.2 \% \\
(18)\end{array}$ & $\begin{array}{l}11.9 \% \\
(26)\end{array}$ & $\begin{array}{c}4.6 \% \\
(10)\end{array}$ \\
\hline 7. An adult showing his private parts to a female child & $\begin{array}{c}62.1 \% \\
(136)\end{array}$ & $\begin{array}{c}13.2 \% \\
(29)\end{array}$ & $\begin{array}{l}20.1 \% \\
(44)\end{array}$ & $\begin{array}{c}4.6 \% \\
(10)\end{array}$ \\
\hline 8. An adult having sexual intercourse with a female child & $\begin{array}{c}93.6 \% \\
(205)\end{array}$ & $\begin{array}{c}1.8 \% \\
(4)\end{array}$ & $\begin{array}{l}1.4 \% \\
(3)\end{array}$ & $\begin{array}{c}3.2 \% \\
(7)\end{array}$ \\
\hline
\end{tabular}

Similarly, only $48.9 \%(n=107)$ indicated touching of their breasts by a lover without permission as an abusive act. Respondents were able to identify adults' sexual behaviours towards children that constituted sexual abuse. Most of the respondents $93.6 \%$, $(n=205)$ identified sexual intercourse that involves an adult and a child as sexual abuse. Some respondents $25.9 \%(n=59)$ felt that a lover touching their breasts without permission was not an abusive act.

Similarly, $23.7 \%(n=52)$ indicated that touching of their private parts by a friend was not a sexually abusive act and as many as $25.6 \%(n=56)$, did not know if the act was abusive. There was no statistically significant difference between the knowledge of abused and non-abused respondents (see Table 2). The majority of respondents $(93.6 \%)$ were aware that sexual abuse is a crime.

\section{Prevalence, forms and frequency of sexual abuse}

The results reveal that sexual abuse begun as early as 4 to 8 years, while $42.2 \%$ $(\mathrm{n}=38)$ indicated they were sexually abused between the ages of 14 and 21 . Ninety respondents $(41 \%)$ admitted to having been sexually abused in their lifetime. Among the eight behaviours listed (refer to Figure 1), touching of breasts in a sexual way was the most common sexually abusive act followed by attempted sexual intercourse. However $18.9 \%(n=17)$ experienced abuse involving sexual intercourse. Of the respondents who were abused $(\mathrm{n}=$ $90), 21 \%(n=19)$ indicated that they had been regularly abused, $76.6 \%(n=69)$ were not regularly abused and $2 \%(n=2)$ did not respond to this question.

\section{Profiles of abusers}

Eighty-nine respondents $(98.9 \%)$ reported that their abusers were males and one respondent $(1.1 \%)$ reported a female abuser. As many as $26.7 \%$ of the abusers were lovers, $33.3 \%$ friends and $20 \%$ relatives. Relatives cited were inlaws ( $11.1 \%)$, cousins $(5.5 \%)$ and uncles $(3.3 \%)$. Two respondents experienced sexual abuse from more than one person; a friend and stranger as well as a relative and stranger. Many abusers' (38.9\%) ages ranged between 21 to 25 years while $30 \%$ were in the age group 16 to 20 years (refer to Figure 2). Respondents who experienced sexual abuse were asked to indicate the tactic that was used by the abuser. Four common behaviours were listed. These were persuasion, threatening to end the relationship, physical threat and bribery. Physical threat was the tactic most reported by respondents $(43.3 \%)$ followed by persuasion $(33.3 \%)$. Tactics used by the abusers were compared to the ages of the victims. No significant pattern was observed. Abusers in all the age groups used all tactics. However, abusers older than 19 years most often used physical threats. One respondent $(1.1 \%)$ indicated that her sexual abuse experience was part of a cultural initiation ritual.

\section{Reporting of sexual abuse experiences $(n=90)$}

Sexual abuse experiences were reported by $55.6 \%(n=50)$ while $44.4 \%(n=40)$ remained silent about their experiences Amongst those who reported, the majority, $27.8 \%$, told their friends, $16.7 \%$ told their mothers only, $7.8 \%$ told family members including sisters, aunts and grandparents. Respondents who did not report sexual abuse provided several reasons. These are the victims' fear of consequences and lack of knowledge that they were being abused. Respondents indicated they would like to know more about the prevention and control of sexual abuse and relevant legal 


\begin{tabular}{|l|c|c|c|c|}
\hline List of behaviours & $\begin{array}{c}\text { Abused } \\
(\mathbf{n}=\mathbf{9 0})\end{array}$ & $\begin{array}{c}\text { Non-abused } \\
(\mathbf{n}=\mathbf{1 2 9})\end{array}$ & Difference \\
\cline { 2 - 5 } & & $\begin{array}{c}\text { Chi } \\
\text { P-value }\end{array}$ & $\begin{array}{c}\text { Fishers } \\
\text { Exact } \\
\text { Test P- } \\
\text { value }\end{array}$ \\
\hline 1. An adult touches buttocks of a female child in a sexual way & 75.6 & 67.4 & 0.2887 & 0.3426 \\
2. Your lover touches your breasts without permission & 55.6 & 44.2 & 0.1317 & 0.1577 \\
3. A friend touches your private parts & 51.1 & 41.1 & 0.1692 & 0.2041 \\
4. A lover has sexual intercourse with you without your permission & 87.8 & 77.5 & $* 0.0543$ & 0.0666 \\
5. An adult kissing a female child in a sexual way & 76.7 & 66.7 & 0.1429 & 0.1593 \\
6. An adult asking a female child to touch his private parts & 78.9 & 72.9 & 0.1785 & 0.2269 \\
7. An adult showing his private parts to a female child 66.7 & 66.7 & 58.9 & 0.1661 & 0.1856 \\
8. An adult having sexual Intercourse with a female child & 92.2 & 94.6 & 0.5270 & 0.7046 \\
\hline
\end{tabular}

* Denotes a significant relationship, $p$ - value of $<0.05$

issues.

\section{Discussion of results}

The findings indicate that most respondents were aged 20 to 21 years in the first year of study at tertiary education institutions in Malawi. All twenty-seven districts and the major and minor Malawian tribes were represented; therefore different cultures were represented in the sample.

Most respondents perceived that sexually abusive behaviours towards children constitute sexual abuse. Respondents were also aware that sexual abuse is a crime, as observed from the reasons given. Although the majority identified elements that constitute sexual abuse, some respondents demonstrated limited knowledge. These respondents were unable to identify certain sexually abusive behaviours, particularly when demonstrated by a friend or lover. The responses may also reflect the cultural beliefs in the Malawian society. The limited knowledge displayed may hamper the exercise of their rights and expose them to the risks associated with sexual abuse. Risks could include early pregnancy and contracting sexually transmitted diseases. The findings in this study are high when compared to similar studies in which a broader definition was made. Amar et al., (1996:489) identified a prevalence rate of $6.3 \%$ among Malaysian female students. Another study conducted by Tang (2002:34) among Chinese college students yielded a prevalence rate of $7 \%$ for females. An explanation of difference in this study's findings compared to the Chinese and Malaysian studies could be the fact that a national sample of students was used in the former and not in the latter. Cultural differences that exist in the different countries may also have contributed to the findings. This may also be true of a study conducted in Geneva by Halperin et al. (1996:1328) in which a national sample of students was used. It concluded that the prevalence rate for females was $33.8 \%$, higher than the one obtained in this study in which a national sample was also used.

The prevalence of sexual abuse in adolescence in the present study (16.4\%) is higher than the $13 \%$ reported by Nagy, Adcock \& Nagy (1994:574). Sexual abuse amongst respondents between 18 and 21 could be related to date and acquaintance rape that this age class is susceptible to (Benson, Charlton, \& Goodhart, 1992:162).
The occurrence of sexual abuse involving sexual intercourse was $18.9 \%(n=17)$. This rate is high compared to prevalence studies conducted in both western and developing countries (compare Halperin et al. 1996; Amar et al. 1996 and Tang, 2002). Sexual abuse involving penetration, such as intercourse may lead to the spread of STIs/HIV which is already prevalent in Malawi. The duration for respondents who were regularly abused ranged from two days to nine years. This was lower than the findings by Amar et al. (1996) in which repeated episodes of abuse were reported in $59.5 \%$ cases. Respondents, who experienced sexual abuse for more than one year, are more likely to identify with the perpetrator, through exploiting others or engaging in antisocial behaviour (Burgess, Hartman, McCausaland \& Powers, 1984:660). Most of the abusers were closely associated to their victims. These results correlate with that of Miller, Monson \& Norton (1995:1292), who found that higher proportions $(78 \%$ and $89 \%$ ) of sexual assaults were perpetrated by persons known to the victim. The fact that one respondent $(1.1 \%)$ admitted that her sexual abuse experience was part of a cultural initiation ritual provides evidence that the ritual exists, although it may also be interpreted that the ritual is no longer 
being practiced widely in Malawi. Alternatively it is possible that respondents did not perceive this aspect to be sexually abusive.

\section{Guidelines for the development of sexual abuse preventive programmes}

Conclusions made from data analysis were used as a basis to formulate guidelines. The researcher further added proposed actions using inductive and deductive logic. Guidelines and actions were developed in the areas of limited knowledge of sexual abuse, prevalence of sexual abuse, common sexual abusive acts, perpetrators of sexual abuse, their victims and the lack of reporting of sexual abuse.

\section{Limitations of the study}

Participants represented literate adolescents and their responses to knowledge regarding sexual abuse may be influenced by access to literature on the subject.

- Respondents who may have been sexually abused may have decided not to disclose their experiences in order to forget previous painful encounters and this might yield an underestimation of the prevalence rates.

- The study included no information about the context or antecedents of the abuse incidents and the victims' subjective feelings.

- Possible recall bias of the respondents who may remember and thus report on more recent traumatic events might have influenced the study.

- The sample incorporated the student female population only and excluded males.

\section{Recommendations}

Recommendations are made for nursing practice, nursing research, nursing education and to the Malawian Government. Early identification of sexual abuse victims is crucial to reduce the suffering of abused females. Professional and enrolled nurses constitute the majority of health care workers in Malawi, therefore they should identify victims of sexual abuse to appropriately manage or refer them. Since there are very few psychiatric nurses in Malawi, it is necessary that nurses who work with children, adolescents and communities are utilised to identify, manage and refer victims. They should have in-service education on sexual abuse. The training should also include other cadres of health workers in similar settings. The curriculum for nurses and other health workers needs to have a strong component of theory, clinical skills and the management of sexual abuse and counselling skills to enable all health workers to provide effective care. Forensic nursing should be introduced in the basic curriculum or as a specialty.

Further research should be conducted especially on the prevalent rates of other at-risk populations, the disabled for example. The observation that a major proportion of perpetrators were in the victim's peer group (16 to 25 years) deserves careful study in relation to sexual behaviour of students.

There is also a need for the government to establish sexual abuse clinics. A multisectoral approach should institute a programme of activities that promotes awareness and knowledge of the subject among the public. Issues of sexuality and self-protection skills should be targeted by parents and schools. Laws relating to sexual abuse in Malawi should be reviewed to determine if the criminal procedures, sentences to abusers and the inclusion of various types of abuse reflect the current societal views and standards.

\section{Conclusion}

Female students in tertiary education institutions in Malawi have limited knowledge of sexual abuse. Victims of sexual abuse come from all the tribes in Malawi. The overall prevalence of sexual abuse is high compared to estimates in western and developing countries. There is a need for health professionals to identify and manage victims of sexual abuse. Preventive programmes should focus on public awareness of what constitutes sexual abuse and its effects to society and human rights.

The study has not only provided descriptive information about sexual abuse but also indicated direction to its prevention and intervention in Malawi.
While the population studied may not be entirely reflective of the adolescent community, it does provide an indication of the prevalence of sexual abuse in Malawi

\section{Acknowledgements}

This study was completed at the Department of Nursing Education, while the second author was a fulltime employee at the University of the Witwatersrand. The article was finally prepared for publication with the assistance of Ms Petra Bester, PhD candidate and research assistant at the North-West University.

Funding: Scholarship and research were funded by the Netherlands Government through ICCO and Christian Health Association of Malawi with the support of the Ministry of Health and Population in Malawi.

Support: The Ministry of Health and Population in Malawi, Mr T Masache, Executive Director of Malawi College of Health Sciences; L Kawala, lecturer, University of Malawi, Kamuzu College of Nursing; Mr E Kachale of JICA, all institutions used in the study and participants.

\section{References}

AMAR, HSS; WONG, WY \& KHATIJAH, HNN 1996: Prevalence of childhood sexual abuse among Malaysian paramedical students. Child abuse and neglect, 20 (6), pp 487-492.

BAGLEY,C; THURSTON, W \& TUTTY, L 1996: Understanding and Preventing Child Sexual Abuse: Critical Summaries of 500 Key Studies. pp. 140-156. UK: Arena.

BAKER,A \& DUNCAN, SP 1985: Child Sex Abuse: A Study of Prevalence in Great Britain. Child Abuse \& Neglect, 9 (4), pp. 457-467.

BENSON, D; CHARLTON, C \& GOODHART, F 1992: Acquaintance Rape on Campus: A Literature Review. Journal of American College Health, 40, pp. 157-165

BURGESS, AW; HARTMAN, CR; McCAUSALAND, MP \& POWERS, $P$ 1984: Response Patterns in Children and Adolescents Exploited through Sex Rings and Pornography. American Journal of Psychiatry, 14, pp. 656 - 662.

CALVERT,JF \& MUNSIE-BENSON,M 
1999: Public Opinion and Knowledge about Childhood Sexual Abuse in a Rural Community. Child Abuse and Neglect, 23 (7), pp. 671-682.

CHEN, X; TYLER, KA; WHITBECK,LB \& HOYT, DR 2004: Early sexual abuse, street adversity, and drug use among female homeless and runaway adolescents in the Midwest. Journal of Drug Issues, 0022-0426/04/01: pp 1-22

DZIMADZI, RK 2002: Knowledge of sexual abuse and prevalence amongst female adolescents in Tertiary Level Educational Institutions in Malawi. Johannesburg: University of the Witwatersrand. (Unpublished M Sc dissertation).

FANSLOW, J \& NORTON, R 1994: Violence against Women: Priorities for Public Health Research in New Zealand. New Zealand Medical Journal, 107 (975), pp 63-64

FENWICK, A 1994: Sexual Abuse in Adults with Learning disabilities. British Journal of Learning Disabilities, 22, pp. 53-56

FINKELHOR, D; HOTALING, G; LEWIS, IA \& SMITH, C 1990: Sexual Abuse in a National Survey of Adult Men and Women: Prevalence, Characteristics, and Risk Factors. Child Abuse and Neglect, 14(1),pp. 19-28

HALPERIN, DS; BOUVIER, P; JAFFE, PD; MOUNOUD, RL; PAWLAK, CH; LAERDACH, J; WICKY, HR \& ASTIE, F 1996: Prevalence of Child Abuse among Adolescents in Geneva: Results of a Cross-sectional survey. British Medical Journal, 312 (7042), pp. 13261329.

HASELTINE,B\& MILTENBERGER,RG 1990: Teaching Self Protection Skills to Persons with Mental Retardation. American Journal of Mental Retardation, 95,pp. 188-197.

HUMANRIGHTS NEEDASSESSMENT SURVEY 1999: Danish Centre for Human Rights. Copenhagen, Denmark.

KAWALA, L. 2000: Sexual Health Knowledge, Attitudes and Practices of High School Students in Lilongwe, Malawi. Lilongwe: University of Malawi (Unpublished).
KEETON, C 2004: Sexual Abuse on the rise in Africa - governments must act. Bulletin of the World Health Organization, 82(4), p313

KEMPE, RS \& KEMPE, CH 1978: Child Abuse. (In Wilson, K. \& James, A 1995: The Child Protection Handbook. London: Bailliere Tindall.

MADU, SN \& PELTZER, K 2001: Prevalence and Patterns of Child Sexual Abuse and Victim Perpetrator Relationship Among Secondary School Students in the Northern Province (South Africa). Archives of Sexual Behaviour. 30 (3), pp 311-321.

McCABE, MP 1993: Sex Education Programmes for People with Mental Retardation. Mental Retardation, 31, pp. 377-387

MILLER, BC; MONSON, BH \& NORTON, MC 1995: The Effects of Forced Sexual Intercourse on White Female Adolescents. Child Abuse and Neglect, 19(10), pp. 1289-1301.

MONTELEONE, JA\& BRODEUR, AE 1998: Child Maltreatment: A Clinical Guide and Reference. St Louis: GW Publishing Inc

NAGY, S \& ADCOCK, A\& NAGY, MC 1994: A Comparison of Risky Health Behaviors of Sexually Active, Sexually Abused, and Abstaining Adolescents. Paediatrics, 93 (4), pp. 570-575.

NAGY, $S \&$ DiCLEMENTE, R \& ADCOCK, AG 1995: Adverse Factors Associated with Forced Sex Among Southern Adolescent Girls. Paediatrics, 96(5), pp. 944 - 946.

NATIONAL AIDS CONTROL PROGRAMME (NACP) 2001: Estimating national HIV prevalence in Malawi from sentinel surveillance data. Lilongwe, Malawi: NACP

RYAN, J \& KING, C 1992: Violence against Women: Clinical Issues, NLN Publications. 41 (2472), pp. 127- 133.

TANG, CS 2002: Childhood Experience of Sexual Abuse among Hong Kong Chinese College Students, Child Abuse and Neglect, 26 (1), pp 23-37.

WILSON, K \& JAMES, A 1995: The
Child Protection Handbook. London: Bailliere Tindall. 